Acta Technologica Agriculturae 2

Nitra, Slovaca Universitas Agriculturae Nitriae, 2021, pp. 92-96

\title{
SPRAY COVERAGE AND BIOLOGICAL EFFICACY OF SINGLE, TWIN SYMMETRICAL, AND TWIN ASYMMETRICAL FLAT FAN NOZZLES
}

\author{
Akbar ALIVERDI*, Masoud BORGHEI \\ Bu-Ali Sina University, Hamedan, I.R. Iran
}

\begin{abstract}
Proper selection of nozzle type and spray volume is essential to optimize herbicide dose, reducing its adverse environmental effects. It has not been sufficiently evaluated which nozzle type (twin symmetrical flat fan nozzle or the twin asymmetrical one) is more efficient and whether pinoxaden application is more efficient at a low or high spray volume. The spray coverage of a single, twin symmetrical, and twin asymmetrical flat fan nozzles, each in the sizes of 110015, 11002, 110025, 11003, 11004 , and 11005 on the moisture-sensitive papers (MSPs) was investigated. The biological efficacy of treatments using pinoxaden against wild oat was investigated. Unlike other nozzle types, the single flat fan nozzle could not cover MSP placed vertically behind the nozzle trajectory. Except for the latter, each nozzle type could cover the MSPs more efficiently with increase in nozzle size. Generally, the nozzles' performance was twin symmetrical > single $=$ twin asymmetrical flat fan nozzles. A larger nozzle size improved the coverage of MSPs but increased the effective dose ( $\mathrm{ED}_{50}$; dose that gives a $50 \%$ reduction in dry weight), indicating a decrease in the efficacy of pinoxaden. Among all treatments, the lowest $\mathrm{ED}_{50}$ value was obtained by the twin symmetrical flat fan nozzle 110015 (5.2 $\mathrm{g}$ a.i. $\left.\mathrm{ha}^{-1}\right)$. The smaller, more concentrated droplets are required to achieve optimal pinoxaden efficacy against wild oat, which can be provided by a twin symmetrical flat fan nozzle with a smaller size.
\end{abstract}

Keywords: graminicide; nozzle type; nozzle size; wild oat

The efficacy of many herbicides, including acetyl CoA carboxylase (ACCase) inhibitors, can be affected by spray volume (Knoche, 1994). Therefore, selecting a proper spray volume is considered a simple method to optimize the herbicide dose (Aliverdi and Zarei, 2020), reducing its adverse environmental effects (Shahgholi et al., 2015). The ACCase inhibitors have shown different behaviour with changing spray volume. In clodinafop-propargyl (Gauvrit and Lamrani, 2008; Naser and Aliverdi, 2020) and sethoxydim (McMullan, 1995), the efficacy increased as spray volume reduced. In fenoxaprop-P-ethyl (Gauvrit and Lamrani, 2008) and fluazifop-p-butyl (Creech et al., 2015a,b), spray volume does not affect the efficacy. In quizalofop-p-ethyl (Sikkema et al., 2008) and cycloxydim (Aliverdi and Karami, 2019), the efficacy increased as spray volume increased. In haloxyfopR-methyl (Buhler and Burnside, 1984), the effect of spray volume on the efficacy depended on species against which it was applied: against Sorghum bicolor, the efficacy increased as spray volume reduced, however, against Setaria lutescens, spray volume did not affect the efficacy. There are two possible methods for adjusting the spray volume changing either the sprayer driving speed or nozzle size. If either a very low or high spray volume is required to achieve optimal herbicide efficacy, the first method's applicability is problematic. For this reason, the second method always seems to be more feasible (Knoche, 1994; Pourdarbani, 2019).

Grassy species, including winter wild oat (Avena sterilis ssp. ludoviciana), should usually be treated with ACCase inhibitors, including pinoxaden, at the three- to four-leaf stage. At such a growth stage, their leaves are almost perpendicular to the ground. When a single flat fan nozzle is used to spray ACCase inhibitors, the spray droplets, which move perpendicular to the ground, impact the leaf surface non-vertically. Hence, it is likely that a large proportion of them will bounce off the leaf surface to the soil surface and be wasted. Moreover, the faster the sprayer driving speed, the more the spray droplets bounce off (Jensen et al., 2001; Jensen, 2012). For this reason, if low spray volume is required, it is necessary to use a small orifice nozzle. Previous research has shown that changing the spray direction from vertical to non-vertical significantly improves the efficacy of haloxyfop-ethoxyethyl (Jensen et al., 2001), clodinafop-propargyl, fluazifop-P-butyl (Jensen, 2012), sethoxydim (Aliverdi, 2018; Aliverdi and Zarei, 2020), cycloxydim, and sethoxydim (Aliverdi and Zarei, 2020). Non-vertical spray can decrease the non-vertical spray droplet impact to the leaf surface (Jensen, 2012). Twin flat fan nozzles create two non-vertical sprays (flat fans), and the angle between them can be symmetrical or asymmetrical. Therefore, they can also decrease the nonvertical spray droplet impact to the leaf surface. There has been already reported better performance for twin flat fan nozzle in contrast to single flat fan nozzle (Nordbo et al., 1995; Combellack et al., 1996; Vallet and Tinet, 2013; Aliverdi, 2018; Aliverdi and Zarei, 2020). They are recommended for application of low spray volumes at high driving speeds (Vallet and Tinet, 2013). 
Although a proper selection of nozzle type and spray volume is essential to optimize the herbicide dose, reducing its adverse environmental effects, the comparative performance assessment of twin symmetrical and twin asymmetrical flat fan nozzles has not been carried out. Furthermore, there is a lack of information on whether the pinoxaden is more effective if applied at a low or high spray volume. Hence, this study intends to fill the gaps mentioned.

\section{Material and methods}

\section{Dose-response study}

The winter wild oat seeds, from which lemma and palea had been removed, were treated using the same method as described by Aliverdi and Zarei (2020). When the coleoptile of seedlings reached $1 \mathrm{~cm}$, they were planted at $1 \mathrm{~cm}$ depth (five seedlings in each 2-I pot $\sim 195$ plant $\cdot \mathrm{m}^{-2}$ ). The pots were filled with a sandy loam soil with $1.1 \%$ organic matter and a pH of 7.6. The pots were placed in the Research Greenhouse of Bu-Ali Sina University, Hamadan, Iran, and irrigated once every five days. The greenhouse temperature was within the range of $17-26{ }^{\circ} \mathrm{C}$ during the day and $12-15^{\circ} \mathrm{C}$ during the night with a natural photoperiod of 11-13 h.

The experiment was performed as a factorial $(6 \times 3 \times 6)$ in a completely randomized design with four replications. Treatments included six doses of pinoxaden $(0,3.75,7.5,15$, 30 , and $60 \mathrm{~g}$ a.i. ha $\left.{ }^{-1}\right)$, which were sprayed using three nozzle types (single, twin symmetrical, and twin asymmetrical flat fan nozzles) of six sizes (110015, 11002, 110025, 11003, 11004, and 11005; which provide 120, 160, 200, 240, 320, and $400 \mathrm{l} \cdot \mathrm{ha}^{-1}$ spray volume, respectively) at the threeleaf stage of winter wild oat. A $20^{\circ}$ forward angled spray and a $20^{\circ}$ rearward angled spray can be provided by twin symmetrical flat fan nozzle, the angle between which is $40^{\circ}$. A $70^{\circ}$ forward angled spray and a $30^{\circ}$ rearward angled spray can be provided by twin asymmetrical flat fan nozzle, the angle between which is $100^{\circ}$. The spray patterns of nozzle types used in the study are illustrated in Fig. 1. At constant pressure of $300 \mathrm{kPa}$ attaining with CFValve ${ }^{\mathrm{TM}}$ (Gate Co., USA) assembled between sprayer lance and nozzle, the range of volume median diameter was 61-105 $\mu \mathrm{m}$ for twin symmetrical and twin asymmetrical flat fan nozzles 110015, 236-340 $\mu \mathrm{m}$ for single flat fan nozzle 11005, and 106-235 $\mu \mathrm{m}$ for other nozzles (MagnoJet, 2020). The treatments were applied with a hand compressor sprayer in the open air outside the greenhouse. Air temperature ranged from $15^{\circ} \mathrm{C}$ to $18{ }^{\circ} \mathrm{C}$, relative humidity ranged from $48 \%$ to $59 \%$, and wind speed ranged from $0.2 \mathrm{~m} \cdot \mathrm{s}^{-1}$ to $0.5 \mathrm{~m} \cdot \mathrm{s}^{-1}$. The pots were placed again in the greenhouse after treatment.

Four weeks after treatment, the plants were harvested $1 \mathrm{~cm}$ above the soil surface, oven-dried at $70{ }^{\circ} \mathrm{C}$ for two days, then weighed to obtain dry weight. The data were analysed by non-linear regression analysis using $\mathrm{R}$ software (Ritz et al., 2015). According to Lack-of-fit test ( $p$-value $>0.05$ ), a logarithmic four-parameter model was identified as a suitable one:

$$
Y=C+\left\{D-C / 1+\exp \left[B\left(\log X-\log E D_{z}\right)\right]\right\}
$$

where:

$Y \quad$ - dry weight

$D$ and $C$ - upper and lower limits for $Y$, respectively

$X$ - dose of pinoxaden

$E D_{z}$ - effective dose $\left(\mathrm{g}\right.$ a.i. $\mathrm{ha}^{-1}$ ) required to reduce the dry weight of winter wild oat by $z \%$ as compared to the control treatment

\section{Spray deposition study}

This study was performed simultaneously with the doseresponse study when $60 \mathrm{~g}$ a.i. $\mathrm{ha}^{-1}$ was being sprayed to investigate the coverage percentage of moisture-sensitive papers (MSP; $26 \times 76 \mathrm{~mm}$ ) from the treatments. The MSPs were placed in three positions (Fig. 2): horizontally on the ground $\left(\mathrm{MSP}_{1}\right)$, vertically in front of the nozzle trajectory

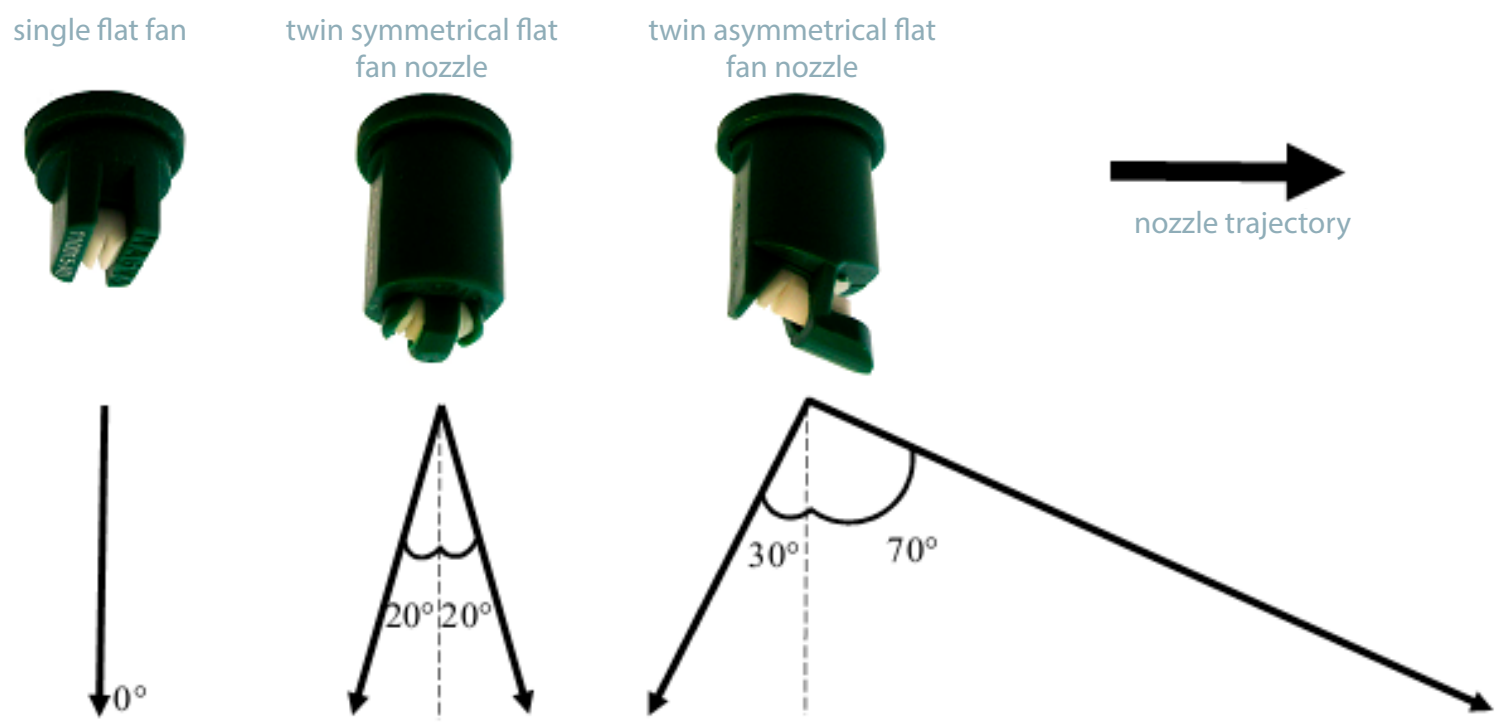

Fig. 1 Spray pattern of nozzle types used in the study 
$\left(\mathrm{MSP}_{2}\right)$, and vertically behind the nozzle trajectory $\left(\mathrm{MSP}_{3}\right)$. For each position, the experiment was performed as a factorial experiment $(3 \times 6)$ in a completely randomized design with three replications; the factor of nozzle type in three levels (single, twin symmetrical, and twin asymmetrical flat fan nozzles) and the factor of nozzle size in six levels $(110015,11002$, $110025,11003,11004$, and 11005).

\section{Nozzle trajectory}

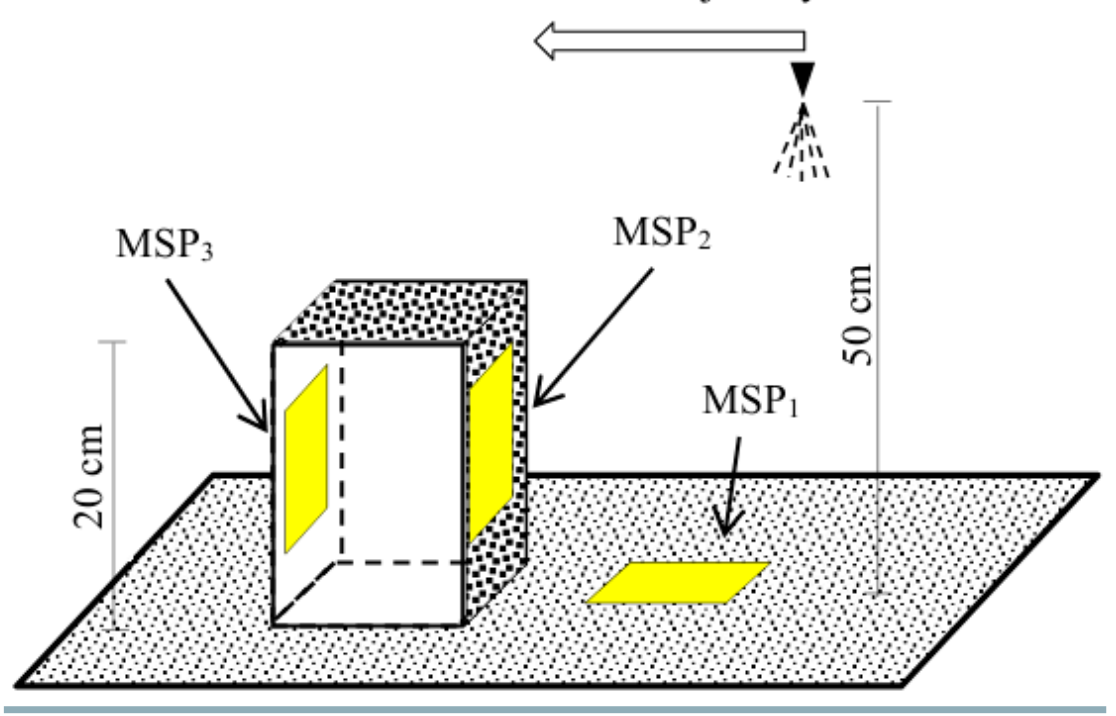

Fig. 2 Position of moisture-sensitive papers (MSP) relative to the nozzle trajectory

Table 1 Effect of nozzle type and size on the coverage of moisture-sensitive papers (MSP) placed in the positions shown in Fig. 2

\begin{tabular}{|c|c|c|c|c|}
\hline Nozzle type & Nozzle size & $\mathrm{MSP}_{1}(\%)$ & $\mathrm{MSP}_{2}(\%)$ & $\mathrm{MSP}_{3}(\%)$ \\
\hline \multirow{6}{*}{ Single flat fan } & 110015 & $24.3 \mathrm{~g}$ & $29.1 \mathrm{f}$ & $0.0 \mathrm{~g}$ \\
\hline & 11002 & $69.2 \mathrm{de}$ & $21.5 \mathrm{~g}$ & $0.3 \mathrm{~g}$ \\
\hline & 110025 & $76.7 c$ & $42.7 \mathrm{de}$ & $0.3 \mathrm{~g}$ \\
\hline & 11003 & $100 \mathrm{a}$ & 40.0 ef & $0.0 \mathrm{~g}$ \\
\hline & 11004 & $100 \mathrm{a}$ & $73.6 \mathrm{~b}$ & $0.0 \mathrm{~g}$ \\
\hline & 11005 & $100 \mathrm{a}$ & $79.2 \mathrm{~b}$ & $0.0 \mathrm{~g}$ \\
\hline \multirow{6}{*}{ Twin symmetrical flat fan } & 110015 & $24.6 \mathrm{~g}$ & 34.3 ef & $12.2 \mathrm{f}$ \\
\hline & 11002 & $72.3 \mathrm{~cd}$ & $62.1 \mathrm{c}$ & $30.1 \mathrm{e}$ \\
\hline & 110025 & $88.1 \mathrm{~b}$ & $72.9 \mathrm{~b}$ & $72.5 \mathrm{c}$ \\
\hline & 11003 & $100 \mathrm{a}$ & $100 \mathrm{a}$ & $97.5 \mathrm{a}$ \\
\hline & 11004 & $100 \mathrm{a}$ & $100 \mathrm{a}$ & $100 \mathrm{a}$ \\
\hline & 11005 & $100 \mathrm{a}$ & $100 \mathrm{a}$ & $100 \mathrm{a}$ \\
\hline \multirow{6}{*}{ Twin asymmetrical flat fan } & 110015 & $12.5 \mathrm{~h}$ & $32.6 f$ & $10.3 \mathrm{f}$ \\
\hline & 11002 & $23.9 \mathrm{~g}$ & $49.3 d$ & $13.2 \mathrm{f}$ \\
\hline & 110025 & $36.4 \mathrm{fg}$ & $49.7 d$ & $38.2 \mathrm{~d}$ \\
\hline & 11003 & $35.4 \mathrm{fg}$ & $100 \mathrm{a}$ & $88.6 \mathrm{~b}$ \\
\hline & 11004 & $40.9 f$ & $100 \mathrm{a}$ & $100 \mathrm{a}$ \\
\hline & 11005 & $63.4 \mathrm{e}$ & $100 \mathrm{a}$ & $100 \mathrm{a}$ \\
\hline
\end{tabular}

In each MSP, the means with a common letter are not statistically different based on Duncan test at the 0.05 probability level
The MSPs were scanned and image-processed in Image J software version 1.48. to detect the spray coverage (\%). A normal distribution of data was stabilized (Shapiro-Wilk test $>0.91$ ). The data were subjected to analysis of variance using SAS software version 4.9. The means were compared using Duncan's test at the level of $5 \%$ probability.

\section{Results and discussion}

The coverage of all MSPs was significantly affected by nozzle type and size. There was an interaction effect between simple effects ( $p$-value $<0.01$ ).

The MSP ${ }_{1}$ was entirely covered by single and twin symmetrical flat fan nozzles in sizes 11003, 11004, and 11005 (Table 1). The MSP 1 was covered minimally $(12.5 \%)$ when the spray solution was applied using the twin asymmetrical flat fan nozzle 110015 . Considering all the nozzle sizes, the $\mathrm{MSP}_{1}$ was covered the least using asymmetrical flat fan nozzle in contrast to other nozzle types. Theoretically, the droplets from the $70^{\circ}$ forward angled spray of asymmetrical flat fan nozzle will have to pass a distance of $146.2 \mathrm{~cm}$ to the MSP ${ }_{1}$ when the height of the nozzle is $50 \mathrm{~cm}$ (distance $=50 / \mathrm{cos}$ $\left.70^{\circ}\right)$. With such a distance, the droplets spend more time in space to the target, causing them most likely to drift.

The $\mathrm{MSP}_{2}$ was entirely covered using the single and twin symmetrical flat fan nozzles in sizes 11003, 11004, and 11005 (Table 1). The $\mathrm{MSP}_{2}$ was covered minimally (21.5\%) when the spray solution was applied by the single flat fan nozzle 11002. In general, the twin flat fan nozzles were more successful in covering the $\mathrm{MSP}_{2}$ than the single flat fan nozzles. Using the single flat fan nozzle, the droplets move vertically from the nozzle to the ground. Therefore, the droplets cannot have an effective impact on the $\mathrm{MSP}_{2}$. Conversely, by the twin flat fan nozzles, the forward angled spray can direct the droplets towards the $\mathrm{MSP}_{2}$, resulting in better coverage. The $\mathrm{MSP}_{3}$ was entirely covered using the twin symmetrical and asymmetrical flat fan nozzles in sizes 11004 and 11005 (Table 1). The performance of the twin symmetrical flat fan nozzle in covering 
$\mathrm{MSP}_{3}$ was better than that of the twin asymmetrical flat fan nozzle. The single flat fan nozzle could not wet $\mathrm{MSP}_{3}$ at all. Except for the latter, all nozzle types showed better coverage of all MSPs with increasing nozzle size. A similar result was reported by Hunter et al. (2019) with the single flat fan nozzle and Naser and Aliverdi (2020) with the single and twin symmetrical flat fan nozzles.

Among all treatments, the lowest values of $\mathrm{ED}_{50}$ and $\mathrm{ED}_{90}$ were observed with the twin symmetrical flat fan nozzle 110015 (5.2 and $21.2 \mathrm{~g}$ a.i. ha $^{-1}$, respectively). The highest values of $\mathrm{ED}_{50}$ and $\mathrm{ED}_{90}$ were observed with the single flat fan nozzle 11005 (39.2 and $91.9 \mathrm{~g}$ a.i. ha ${ }^{-1}$, respectively) (Table 2 ). In other words, the performance of the twin symmetrical flat fan nozzle 110015 was 5.2 times higher based on $\mathrm{ED}_{50}$ and 4.3 times higher based on $\mathrm{ED}_{90}$ than that of the single flat fan nozzle 11005. In all nozzle types, the $E_{50}$ and $E_{90}$ values increased significantly with increasing the nozzle size (spray volume). Therefore, there was found a negative relationship

Table 2 Effective dose (ED) of pinoxaden required to reduce the dry weight of wild oat by $50 \%$ and $90 \%$ compared to control treatment

\begin{tabular}{|c|c|c|c|}
\hline Nozzle type & Nozzle size & $E D_{50}\left(g\right.$ a.i. $\left.h a^{-1}\right)$ & $E D_{90}\left(g\right.$ a.i. $\left.h a^{-1}\right)$ \\
\hline \multirow{6}{*}{ Single flat fan } & 110015 & $8.8(0.1) c$ & $33.9(1.6) \mathrm{cd}$ \\
\hline & 11002 & $11.3(0.8) \mathrm{e}$ & $35.6(0.9) d$ \\
\hline & 110025 & $11.0(0.6) \mathrm{e}$ & $41.5(0.8) f$ \\
\hline & 11003 & $17.7(0.9) \mathrm{g}$ & $47.0(2.0) \mathrm{g}$ \\
\hline & 11004 & $22.4(0.9) \mathrm{i}$ & $59.6(0.7) \mathrm{i}$ \\
\hline & 11005 & $27.2(1.1) \mathrm{j}$ & $91.9(3.1) \mathrm{k}$ \\
\hline \multirow{6}{*}{ Twin symmetrical flat fan } & 110015 & $5.2(0.3) \mathrm{a}$ & $21.2(0.5) \mathrm{a}$ \\
\hline & 11002 & $7.7(0.3) b$ & $24.2(1.9) b$ \\
\hline & 110025 & $8.9(0.5) c$ & $41.7(1.2) f$ \\
\hline & 11003 & $10.4(0.5)$ de & $39.9(0.4)$ e \\
\hline & 11004 & $12.6(0.8)$ ef & $55.5(0.9) \mathrm{h}$ \\
\hline & 11005 & 10.2 (0.9) de & $54.0(2.7) \mathrm{h}$ \\
\hline \multirow{6}{*}{ Twin asymmetrical flat fan } & 110015 & $9.8(0.3) d$ & $25.4(1.5) b$ \\
\hline & 11002 & $12.6(0.4) \mathrm{f}$ & $30.6(2.3) \mathrm{c}$ \\
\hline & 110025 & $13.7(0.7) f$ & $48.8(0.9) \mathrm{g}$ \\
\hline & 11003 & $19.3(1.3) \mathrm{h}$ & $61.7(1.7) \mathrm{i}$ \\
\hline & 11004 & $22.0(1.3) \mathrm{i}$ & $70.8(1.6) \mathrm{j}$ \\
\hline & 11005 & $22.7(1.8) \mathrm{i}$ & $68.1(2.4) \mathrm{j}$ \\
\hline
\end{tabular}

Standard errors are in parentheses. In each ED, the values with the same letter are not different $(p<0.05)$

between spray volume and the efficacy of pinoxaden against winter wild oat. Moreover, this relationship was more negative when the single fan nozzle was used. A $65 \%$ and a $64 \%$ increase in the $\mathrm{ED}_{50}$ and $\mathrm{ED}_{90}$ values, respectively, occurred when the size of the single fan nozzle increased from 110015 to 11005. A 49\% and a 59\% increase in the $\mathrm{ED}_{50}$ and $\mathrm{ED}_{90}$ values, respectively, occurred when the size of the twin symmetrical fan nozzle increased from 110015 to 11005 . A $57 \%$ and a $62 \%$ increase in the $\mathrm{ED}_{50}$ and $\mathrm{ED}_{90}$ values, respectively, occurred when the size of the twin asymmetrical fan nozzle increased from 110015 to 11005 . As mentioned above, previous studies have reported a positive, neutral, or negative relationship between spray volume and the efficacy of ACCase inhibitors. In case of pinoxaden, the results showed that a larger nozzle size could improve the coverage of MSPs (Table 1), but it decreased the efficacy (Table 2). Increased efficacy of pinoxaden when spray volume was reduced can be due to certain reasons. The smaller the size nozzle, of spray and leaves of grassy species are
relatively perpendicularly oriented to the ground.

Therefore, the impact angle of droplets on the leaves is most likely low. Hence, it is likely that a large number of them will bounce off the leaf surface to the soil surface and be wasted. Simultaneously, the latter creates two non-vertical sprays, which leads to a situation when the impact angle of droplets on the leaves is most likely high, reducing the number of the droplets bounced off (Jensen et al., 2001; Dorr et al., 2015). At the same size as the latter, the former will always show smaller droplet size due to atomizing through two orifices. This is true even for sizes 11002, 110025 , 11003, and 11004. Although the former is provided with a similar spray classification as the latter (MagnoJet, 2020), we know that the latter has to have a smaller average droplet size. As mentioned above, smaller droplets may deposit better over the leaf surface, resulting in improved herbicide efficacy (Butts et al. 2018). In our previous study, an increased number of flat fans (single, twin symmetrical, and 
triplet-orifice flat fan nozzles) reduced the values of $\mathrm{ED}_{50}$ for cycloxydim against wild barley (Aliverdi and Karami, 2019). In the current study, however, the performance of twin fan asymmetrical flat fan nozzle was equal to that of the single flat fan nozzle. This weakness can be due to the fact that the droplets produced by the $70^{\circ}$ forward angled spray of twin fan asymmetrical nozzle are driftable (Table 1).

\section{Conclusion}

Based on the literature review, the efficacy of herbicides is correlated with spray volume, which can be identified only by experiment. Current results accepted this theory found in the literature. In all nozzle types, the efficacy of pinoxaden against winter wild oat increased with decreasing the nozzle size (spray volume), indicating a requirement for the smaller, more concentrated droplets to achieve the optimal pinoxaden efficacy. Using low spray volume not only improves the efficacy of pinoxaden but is also economically advantageous in terms of water-saving. Regardless of the type of nozzle, such droplets can be produced with the nozzle size of 110015 . Based on the results of spray deposition study, it seems that the front of plant was weakly covered using the twin asymmetrical flat fan nozzle and the back of plant cannot be wetted using the single flat fan nozzle at all. The twin symmetrical flat fan nozzle showed none of these weaknesses. As a result, regardless of the nozzle size, the highest pinoxaden efficacy was observed using the twin symmetrical flat fan nozzle. Current results suggest that the twin symmetrical flat fan nozzle of size 110015 can be selected as a proper nozzle type for producing the appropriate spray volume for pinoxaden application against winter wild oat.

\section{Acknowledgements}

This work was funded by Bu-Ali Sina University. No conflicts of interest have been declared.

\section{References}

ALIVERDI, A. 2018. The selection of proper nozzle for spraying sethoxydim at two wind speeds to control winter wild oat (Avena sterilis ssp. ludoviciana). In Journal of Plant Protection, vol. 32 no. 2, pp. 299-306.

ALIVERDI, A. - KARAMI, S. 2019. The effect of type and size of single, twin, and triplet flat fan nozzles on the activity of cycloxydim against wild barley (Hordeum spontaneum Koch.). In Journal of Plant Protection, vol. 33, no. 3, pp. 465-474.

ALIVERDI, A. - ZAREI, M. 2020. Forward angled spray: a method for improving the efficacy of herbicides. In Journal of Plant Protection Research, vol. 60, no. 3, pp. 275-283.

BUHLER, D. D. - BURNSIDE O. C. 1984. Effect of application factors on postemergence phytotoxicity of fluazifop-butyl, haloxyfop-methyl, and sethoxydim. In Weed Science, vol. 32, no. 5, pp. 574-583.

BUTTS, T. R. - SAMPLES, C. A. - FRANCA, L. X. - DODDS, D. M. - REYNOLDS, D. B. - ADAMS, J. W. - ZOLLINGER, R. K. - HOWATT, K. A. - FRITZ, B. K. - CLINT, H. W. - KRUGER, G. R. 2018. Spray droplet size and carrier volume effect on dicamba and glufosinate efficacy. In Pest Management Science, vol. 74, no. 9, pp. 2020-2029.

COMBELLACK, J. H. - WESTERN, N. M. - RICHARDSON, R. G. 1996. A comparison of the drift potential of a novel twin fluid nozzle with conventional low volume flat fan nozzles when using a range of adjuvants. In Crop Protection, vol. 15, no. 2, pp. 147-152.
CREECH, C. F. - HENRY, R. S. - FRITZ, B. K. - KRUGER, G. R. 2015 a. Influence of herbicide active ingredient, nozzle type, orifice size, spray pressure, and carrier volume rate on spray droplet size characteristics. In Weed Technology, vol. 29, no. 2, pp. 298-310.

CREECH, C. F. - HENRY, R. S. - WERLE, R. - SANDELL, L. D. - HEWITT, A. J. - KRUGER, G. R. 2015b. Performance of post-emergent herbicides applied at different carrier volume rates. In Weed Technology, vol. 29, no. 3, pp. 611-624.

DORR, G. J. - WANG, S. - MAYO, L. C. - MCCUE, S. W. - FORSTER, W. A. - HANAN, J. - HE, X. 2015. Impaction of spray droplets on leaves: influence of formulation and leaf character on shatter, bounce and adhesion. In Experiments in Fluids, vol. 56, no. 143.

GAUVRIT, C. - LAMRANI, T. 2008. Influence of application volume on the efficacy of clodinafop-propargyl and fenoxaprop-P-ethyl on oats. In Weed Research, vol. 48, no. 1, pp. 78-84.

HUNTER, J. E. - GANNON, T. W. - RICHARDSON, R. J. - YELVERTON, F. H. - LEON, R. G. 2019. Coverage and drift potential associated with nozzle and speed selection for herbicide applications using an unmanned aerial sprayer. In Weed Technology, vol. 34, no. 2, pp. 235-240.

JENSEN, P. K. 2012. Increasing efficacy of graminicides with a forward angled spray. In Crop Protection, vol. 32, pp. 17-23.

JENSEN, P. K. - JORGENSEN, L. N. - KIRKNEL, E. 2001. Biological efficacy of herbicides and fungicides applied with low-drift and twin-fluid nozzles. In Crop Protection, vol. 20, no. 1, pp. 57-64.

KNOCHE, M. 1994. Effect of droplet size and carrier volume on performance of foliage-applied herbicides. In Crop Protection, vol. 13, no. 3, pp. 163-178.

MAGNOJET. 2020. Product Catalogue. Available at: http://www. magnojet.com.br/produtos

MCMULLAN, P. M. 1995. Effect of spray volume, spray pressure and adjuvant volume on efficacy of sethoxydim and fenoxaprop-pethyl. In Crop Protection, vol. 14, no. 7, pp. 549-554.

NASER, N. - ALIVERDI, A. 2020. Effect of nozzle type and spray volume on clodinafop-propargyl efficacy in winter wild oat (Avena sterilis subsp. Iudoviciana Durieu.) control. In Iranian Journal of Weed Science, vol. 16, no. 1, pp. 37-48.

NORDBO, E. - STEERMEN, J. K. - KITKNELT, E. 1995. Deposition and efficiency of herbicide sprays in sugar beet with twin-fluid, low-drift and conventional hydraulic nozzles. In Crop Protection, vol. 14, no. 3, pp. 237-240.

POURDARBANI, R. 2019. Choosing a proper maintenance and repair strategy for tractors (in Urmia). In Acta Technologica Agriculturae, vol. 22, no. 1, pp. 12-16.

RITZ, C. - BATY, F. - STREIBIG, J. C. - GERHARD, D. 2015. Doseresponse analysis using R. In PLoS One, vol. 10, no. 12, pp. e0146021. SHAHGHOLI, H. - MAKARIAN, H. - SHOKATI, B. -TALAEI, G. H. ASGHARIPOUR, M. R. 2015. Do tillage methods affect germination and species similarity of soil weed seeds bank? In Acta Technologica Agriculturae, vol. 18, no. 4, pp. 97-101

SIKKEMA, P. H. - BROWN, L. - SHROPSHIRE, C. - SPIESER, H. SOLTANI, N. 2008. Flat fan and air induction nozzles affect soybean herbicide efficacy. In Weed Biology and Management, vol. 8, no. 1, pp. 31-38.

VALLET, A. - TINET, C. 2013. Characteristics of droplets from single and twin jet air induction nozzles: A preliminary investigation. In Crop Protection, vol. 48, pp. 63-68. 